\title{
Self-disclosure and self-deprecating self-reference: Conversational practices of personalization in police interviews with children reporting alleged sexual offenses
}

\author{
Carrie Childs $^{a, *}$, Dave Walsh ${ }^{b}$ \\ ${ }^{a}$ Department of Life Sciences, University of Derby, Kedleston Road, Derby, England DE22 1GB, United Kingdom \\ ${ }^{\mathrm{b}}$ Department of Law and Criminology, University of Derby, One Friar Gate Square, Derby, England DE1 1DZ, United Kingdom
}

Received 15 August 2016; received in revised form 3 October 2017; accepted 8 October 2017

\begin{abstract}
This article examines how police officers ostensibly reveal personal information about themselves in investigative interviews with children reporting their being victim of alleged sexual offenses. We identify two practices of personalization. First, we show how, during the opening phase of interviews, officers engage in clear, unambiguous self-disclosure and how these self-disclosures are designed to elicit expressions of affiliation from witnesses. Second, we identify instances of self-deprecating self-reference as in 'l'm going deaf that's all'. These self-references are delivered to manage trouble responsibility in environments of repair. We show how they manage the conflicting demands of rapport building and the requirement to make interviewees feel as if they are being listened to and understood, on the one hand, and the need for effective evidence gathering, on the other. The present study extends understanding of how officers personalize the investigative interview, as recommended by best practice guidelines.
\end{abstract}

(C) 2017 Elsevier B.V. All rights reserved.

Keywords: Self-reference; Self-deprecation; Self-disclosure; Police interviewing

\section{Introduction}

Investigative interviewing of children who allege their being victims of sexual offenses can be a demanding task for both interviewer and interviewee. As outlined in best practice guidelines such as Achieving Best Evidence in Criminal Proceedings: Guidance on Using Special Measures (henceforth ABE), published by the Ministry of Justice in 2011, interviews with children in England and Wales are mandatorily video-recorded by the police and these recordings serve two main purposes. The first is the gathering of evidence for use in the investigation and in criminal proceedings; the second is the evidence in-chief of the witness; child witnesses under the age of eighteen will normally give their evidence outside of the courtroom by playing the video recorded interview as evidence in-chief. This enables children to undergo less rigorous questioning while in court, but places greater emphasis on the police interview to form a key aspect of the evidence in the investigation. In investigations that lack technical evidence, as occurs frequently in cases of alleged

\footnotetext{
* Corresponding author.

E-mail addresses: C.childs@derby.ac.uk (C. Childs), D.walsh@derby.ac.uk (D. Walsh).
} 
sexual offenses, the content of police interviews with suspects, witnesses and victims often completely decide the success of a given crime investigation (Holmberg, 2004). Such a central role means that it is vital that officers undertake appropriate measures when interviewing children to gain reliable and comprehensive accounts.

The present study examines how police officers ostensibly reveal personal information about themselves in investigative interviews with children reporting their being victim of alleged sexual offenses. We focus on two versions of the practice. First, we focus on cases of clear, unambiguous self-disclosure (e.g. "if it makes you feel any better to start off with I do feel a little bit nervous"). These self-disclosures take the form of assessments and build on and affiliate with interviewees' prior assessments. As Clark et al. (2003) note, such assessments are a way of encouraging a further affiliative assessment from an interlocutor and are "a particularly important form of rapport as they comprise occurrences of these parties showing co-participation and social solidarity to one other" (p. 6). These self-disclosures are confined to opening phases of interviews, during which officers should be concerned with "personalizing the interview, building rapport and engaging the witness" (ABE, 2011, p. 187). We show how these self-disclosures are designed to build extended sequences of rapport, which may hinder evidence gathering in subsequent interview phases. Second, we outline instances of self-deprecating self-reference (henceforth SDSR) (e.g. "I'm going deaf that's all") as a practice for managing the conflicting demands of rapport building. On the one hand, establishing rapport involves appearing engaged, listening attentively and responding appropriately. A basic principle as outlined in ABE is to "listen to the witness" (p. 11). On the other hand, effective evidence gathering (where repeated and/or intensive questioning can often be undertaken) possesses the risk of giving the impression to the interviewee that either they are not being listened to, believed or understood. This is significant as Back et al. (2011) note that sexually abused children report the questioning by the police as a strange and unknown experience and when police, for example, call into question statements made about the abuse, children may feel that they are viewed as unreliable. Further, they may become "doubtful about their own narrative about the sexual abuse" (p. 53). It is imperative then, that intensive questioning is undertaken in such a way that children feel supported and understood. We how SDSR is a means of achieving this and managing the conflict between appearing engaged and listening attentively one the one hand, and engaging in repeated and/or intensive questioning for the purposes of effective evidence gathering, on the other.

Relatedly, conversation analytic research has shown that practices of other-initiation of repair (henceforth OIR) are vulnerable to communicating the stance that responsibility for the trouble lies with the speaker whose talk inspired the repair initiation (Robinson, 2006). That is, that fault lies with the interviewee, such as problems with their speaking. We show how SDSR is a specific type of self-disclosure with specific implications for matters of rapport, particularly in environments of repair. They are routinely delivered as an account as interviewers manage responsibility for repair related trouble by claiming this to be a matter of their own impairment. Further, we show how this practice may be used by officers to "personalize the interview" (ABE, 2011, p. 187) outside of the opening phase. This is significant as guidelines stress that "rapport should not be regarded as something that is confined to the first phase of the interview" (ABE, p. 188).

\subsection{Interactional studies of self-disclosure}

Work within conversation analysis has documented practices of self-disclosure. Antaki et al. (2005) show how, in everyday talk, speakers design their talk to come off as disclosive. They argue that revelations of personal information in and of themselves are insufficient as "no list of topics can hope to capture what comes off as a self-disclosure" (p. 186). They outline several features that work together for something to be heard as a self-disclosure; first, talk must be designed to be heard as a report of personal information rather than some other conversational move (this may be achieved, for example, through features such as news-casting). Second, the report must be designed to be heard as significant or newsworthy in the circumstances (for example by describing experiences in exaggerated terms such as 'I'm the world's worst cook'). Finally, the report must be designed to be heard as over and above what is required by the interactional business at hand (for example, using turn initial particles such as 'as a matter of fact'). This work has implications for research on self-disclosure as "if psychologists want to assess it, it would be better if they first had the means of recognizing it, and what it does in interaction" (p. 183).

Research within various institutional settings has revealed how self-disclosure may have clear institutional functions. For example, Leudar et al. (2006) discuss psychotherapists' disclosures of personal information to their clients during therapeutic sessions. They show how therapists' disclosures are designed as experiential matches (Heritage and Lindström, 1998) that match an element of the client's talk. They function to normalize or mitigate the client's expressed problematic experiences. Stokoe (2009) documented practices of self-reference in police interviews with suspects, examining how, when and for what interactional purposes officers disclose personal information. These rare instances of self-reference have clear functions such as to affiliate with suspects or to pursue an admission or confession. Rather than being organized randomly, interviewers' self-references have clear interactional functions within suspect interviews. The present study develops this work and considers police officer's uses of SDSR in police interviews with child witnesses. 


\subsection{Building rapport and personalizing witness interviews}

Rapport ${ }^{1}$ has be defined as a "harmonious, empathetic, or sympathetic relation or connection to another self" (Newberry and Stubbs, 1997:14). One recommendation for increasing rapport is that investigators are "attentive both to the speech (what's said and not said) and to the behavior (non-verbal indicators, emotions) of his or her interlocutor" (St Yves, 2006, p. 91). St-Ives also notes that paying attention is essential and argues that "many investigators do not know how to listen" (p. 94). The importance of rapport building is well documented, and is an important component in creating the right climate for an interviewee to provide information by reducing anxiety (Collins et al., 2002; Fisher and Geiselman, 1992; Hershkowitz, 2011; Roberts et al., 2004), as anxiety may be a barrier to effective evidence gathering by making it difficult for children to focus adequately (Quas and Lench, 2007). In sum, rapport is essential to build conditions where children feel comfortable in fully disclosing often painful and embarrassing details and is considered a vital component of successful interviews. Nevertheless, it is unclear what constitutes rapport and the literature lacks suggestions of how rapport building may be guaranteed (Collins et al., 2005). Perhaps unsurprisingly, it is well documented that rapport building approaches are often less than satisfactory (Walsh and Bull, 2012; Westcott and Kynan, 2006; Wood et al., 1996).

A live issue for officers is dealing with the discordant demands of rapport building, on the one hand, and effective evidence gathering, on the other. Antaki et al. (2015) discuss how officers deal with the conflicting demands of dealing with distress of adults with intellectual disabilities alleging sexual assault, while maintaining impartiality. They note that due to constraints imposed by the acceptability of evidence in court, and the need to avoid to be seen as leading a witness when dealing with interviewees' expressed distress, it is difficult for officers to do more than acknowledge that the interviewee is experiencing something that may impede the telling of their story. As such, officers are institutionally obliged to favor forensic probity over empathy.

One element of building rapport (stressed both in the empirical literature and in interviewing guidelines) involves personalizing the interview by engaging in self-disclosure, which is widely defined as transmitting personal information to another (Collins and Miller, 1994). ABE (2011) recommends that officers 'talk about themselves too' in order to 'make the interviewer more identifiable' (p. 188). In their study of rapport building with adult witnesses, Vallano and Schreiber Compo (2011) found that, contrary to the principles that underpin best practice guidelines, witnesses felt interviewers' self-disclosure was not conducive to their revealing more details. However this may very well depend on the nature of what is being revealed. Interviewers in their study revealed, for example, that they shared similar numbers of siblings as the interviewee. In contrast, Vallano and Schreiber Compo also found that when self-disclosure was absent participants rated the interview as being overly formal. As such, these authors argue that future research should examine what types of personal revelations are appropriate. Further, they note that it remains unknown what techniques of revealing personal information are effective in investigative interviews conducted by the police with children and adolescents.

Engaging in self-disclosure in the hope that the interviewee will trust officers and will reciprocate by also revealing personal information is a strategy that police detectives report using during interviews (Soukara et al., 2002). Work in Conversation Analysis has shown that typically, in everyday talk, self-disclosures provide for the relevance of, and engender, recipient's second self-disclosures, similarly to how a story or other activity is often followed by a second (Sacks, 1992). Encouraging interviewees to talk about themselves then, is one purpose of officers talking about themselves. In addition, personalizing the encounter may improve witnesses' experiences of the interview. This is important as it is well established that investigative interviews are, for many, a traumatic experience. Adolescent victims of sexual assault have reported that officers adopting a 'personable touch' including "sharing personal information about their own lives" (Greeson et al., 2014, p. 647) may result in a more comfortable experience.

It is clear then, that revealing personal information during the course of interviews promotes rapport building. However doing so appears to be somewhat of a minefield, and it has been suggested that officers should proceed with caution. St Yves (2006) argues that a professional approach precludes personal self-disclosure. It has been suggested that inappropriate disclosures may result in officers being viewed as unprofessional (Vallano and Schreiber Compo, 2011), potentially undermining interviewee's respect for the interviewer (Abbe and Brandon, 2013). It is likely that "interviewer self-disclosure may be a more effective rapport-building technique within an investigative interview if it is context-appropriate" (Vallano and Schreiber Compo, 2011, p. 966). In spite of this, guidelines are vague and abstract. Little is known about how in practice, officers actually engage in 'self-disclosure' and reveal personal information during interviews with witnesses. In the empirical literature self-disclosure is typically operationalized as an independent variable (c.f. Antaki et al., 2005) that has a causal effect on variables such as liking, positivity and

\footnotetext{
${ }^{1}$ This is distinct from, although related to, the notion of rapport as the management of face and the management of sociality rights (SpencerOatey, 2000) as commonly cited in pragmatics
} 
familiarity (e.g. Collins and Miller, 1994; Sprecher et al., 2013). This approach inhibits any insight into the practices of how interviewers bring off revelations of personal information and the interactional function of these revelations. In contrast, a conversation analytic approach facilitates a fine grain analysis of the action orientation of talk and what interviewer's 'self-disclosures' may be designed to do.

\section{Methodology}

The dataset comprises twenty-nine field videos of interviews with children reporting their being victim of alleged sexual offenses collected from one police constabulary in England. The selection of videos was made by local police personnel. The interviews were carried out between March 2010 and December 2012 and were all cases that had been concluded either by successful prosecution, or by earlier case disposal (including discontinuance). These interviews were undertaken by twelve different trained officers and lasted between twenty five and one hundred and eleven minutes. The recordings were irrevocably anonymised by the researchers on police premises. As such all names found in this paper (including place names) are pseudonyms. The original corpus comprised thirty interviews and we excluded one recording where the interviewee was a mature woman. One child was of pre-school age (six years) and the remaining twenty eight were of school age (between ten and sixteen). Children's testimony is routinely video recorded in England and Wales. Consent for videos to be used for training, audit and other official purposes such as research is standardly requested at the conclusion of any criminal or civil proceedings, or when no proceedings are to be initiated. Orthographic transcripts of each video were created and a broad search of materials was used to select a corpus of candidate self-reference. This search yielded seventeen candidate examples of self-reference. Of these, three are examples of clear unambiguous selfdisclosure. Six are examples of SDSR. The remaining eight occur in the turn at talk during which police officers introduce themselves. Typically, these turns consist of officers' names, Force Identification Number (used to identify police staff) and an indication of the officers' place of work. In eight examples officers provide information that is over and above this (such as 'I'm a police officer, I don't wear a uniform obviously, cause I don't want, if we are interviewing children I don't want them to be scared to death of things like wearing a uniform'). Discussion of these is beyond the scope of this paper. Phenomena of interest were transcribed using the Jefferson notation system (see Hepburn and Bolden, 2017). Analysis was conducted using Conversation Analysis to identify the sequential environments in which instances of self-reference occurred and the interactional function accomplished by each example.

\section{Results}

The first part of the analysis focusses on clear, unambiguous examples of self-disclosure as identified by Antaki et al. (2005). These examples, which are confined to the opening phase of interviews, are designed as reports of personal information and as such are brought off as self-disclosive. The second part of the analysis turns to instances of SDSR. This section is divided into two further sub-sections. The first of these shows how SDSR may be deployed as a way of managing responsibility in environments of repair. The second outlines how SDSR refute the notion that the interviewer may be inattentive to the interviewee by formulating the trouble as a matter of interviewer impairment.

\subsection{Self-disclosure}

Clear, unambiguous self-disclosures as outlined by Antaki et al. (2005) are rare within our materials, with three examples across the dataset. These examples occur within the opening phase of the interview, the aim of which is to personalize the interview, build rapport and engage the witness (ABE, 2011) in order to improve the accuracy and quantity of information obtained during the subsequent phases of the interview. Two examples are presented here.

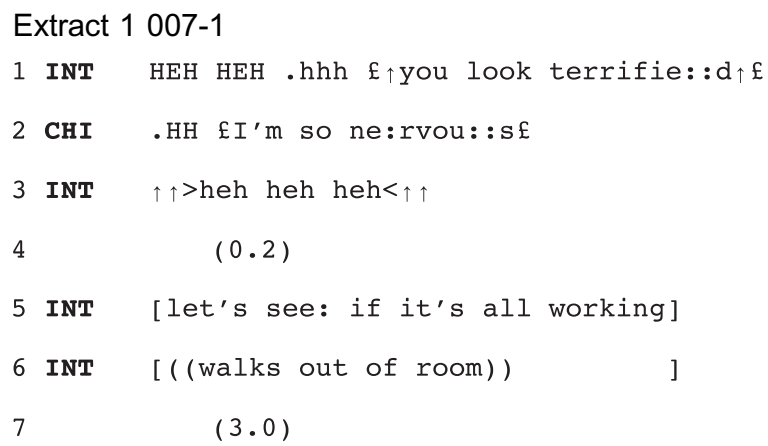




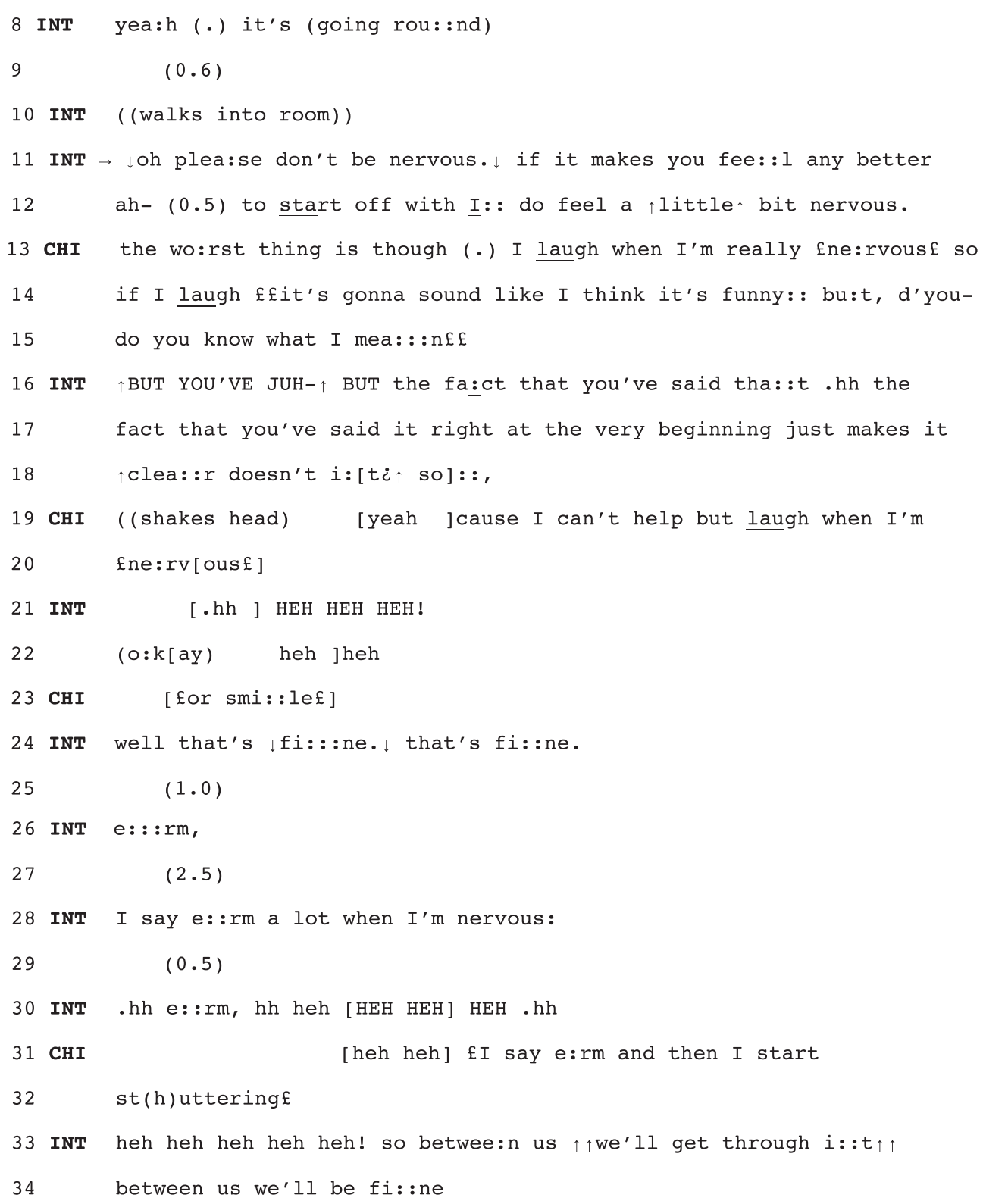

This extract is taken from the very start of the recording, as the interviewer enters the room. In the turn at line 1 the interviewer assesses the interviewee's appearance; ' $£ \uparrow$ you look terrifie::d $\uparrow £$ '. This extreme case formulation (Pomerantz, 1986) is preceded by laughter particles and is delivered in 'smiley voice', evidencing the turn's nonliteral orientation (Edwards, 2000). The interviewee ratifies this assessment, downgrading the appraisal from 'terrified' to 'nervous'.

After leaving the room to confirm that the recording equipment is running (lines 5-8) the interviewer reenters the room and delivers the pleading 'oh plea:se don't be nervous'. In the second turn construction unit (TCU) she delivers the target expression 'if it makes you fee::I any better ah- (0.5) to start off with l:: do feel a $\uparrow$ little $\uparrow$ bit nervous.'. This reciprocal selfdisclosure is occasioned by the interviewee's claim to be 'nervous' and as such is brought off as designedly empathetic, produced in the service of acknowledging and alleviating the interviewee's displayed anxiety. The contrastive stress on the personal pronoun 'l:.:' implicitly indexes the expectation that, in contrast to the to-be-expected anxiety of interviewees, the interviewer would ordinarily be expected to go about their job without experiencing anxiety. As such this admission serves to normalize and empathise with the interviewee's nervousness.

Several design features evidence the turn's status as a clear, unambiguous self-disclosure. First, the preface 'if it makes you fee::I any better' casts the report as dramatic in the circumstances of the interaction- it is 'confessional' in 
nature. This confessional nature is further developed with the 'l:: do' and the minimizer 'a $\uparrow$ little $\uparrow$ bit'. The preface 'if it makes you fee::I any better' also designs the turn as volunteered and superfluous- it is over and above what is required in this environment. In sum, the turn is clearly brought off as a revelation of personal information and is 'hearable as a report and not some other conversational move' (Antaki et al., 2005, p. 188).

We may also note that by discussing her own experiences of nervousness, the interviewer affiliates with and builds on the interviewee's previous assessment. Such assessments are a way of encouraging a further affiliative assessment from the prior speaker (Clark et al., 2003). The interviewee affiliates with and builds on this by disclosing that 'the wo:rst thing is though (.) I laugh when I'm really £ne:rvous£', providing a preemptive account such that any laughter during the course of the interview should be ascribed to her 'nervousness', rather than the circumstances of the interaction. This turn is built for a response with the tag question 'do you know what I mea:::n££' and in the turn at lines 16-18 the interviewer extends the sequence with a further affiliative assessment, providing reassurance that disclosing this at the 'very beginning just makes it $\uparrow$ clea::r doesn't i:t $i \uparrow s$ o:.:, . The interviewee breaks into this turn, delivering the self-disclosive 'yeah cause I can't help but laugh when I'm £ne:rvous£'. This extended sequence of mutual expressions of affiliation comes to a point of possible closure with the interviewer's 'well that's $\downarrow$ fi:::ne. $\downarrow$ that's fi::ne.', which is delivered with falling intonation. Following a lag, the interviewer hedges 'e:::rm,' and reinitiates the topic with a further self-disclosive assessment 'I say e::rm a lot when l'm nervous:'. She delivers a further 'e::.:rm,'at line 26, demonstrating, rather than claiming, solidarity and the experience of nervousness. She then invites the interviewee to share laughter. The interviewee joins in before delivering similar self-disclosive assessment that builds on the interviewer's disclosure ' $£$ l say e:rm and then I start st(h)uttering£'.

As Clark et al. (2003) note, such extended sequences of mutual expressions of affiliation are indicative of verbal rapport. Police detectives report that they reveal personal information in the hope that interviewees will also divulge personal information (Soukara et al., 2002). This is not unlikely as, in everyday talk, self-disclosures provide for the relevance of recipient's second self-disclosures (Sacks, 1992). Offering an assessment that builds on and trades off interviewee's prior assessment mobilizes reciprocity and elicits an expression of affiliation from the interviewee.

The example in extract 2 is similarly designed as a volunteered revelation of personal information that provides for the relevance of a second self-disclosure. The example also takes the form of an assessment that builds on a prior assessment. The extract begins shortly after the interviewer enters the room. Before this, a social worker (who is present for the duration of the interview) and the interviewee have been discussing studying mathematics in school.

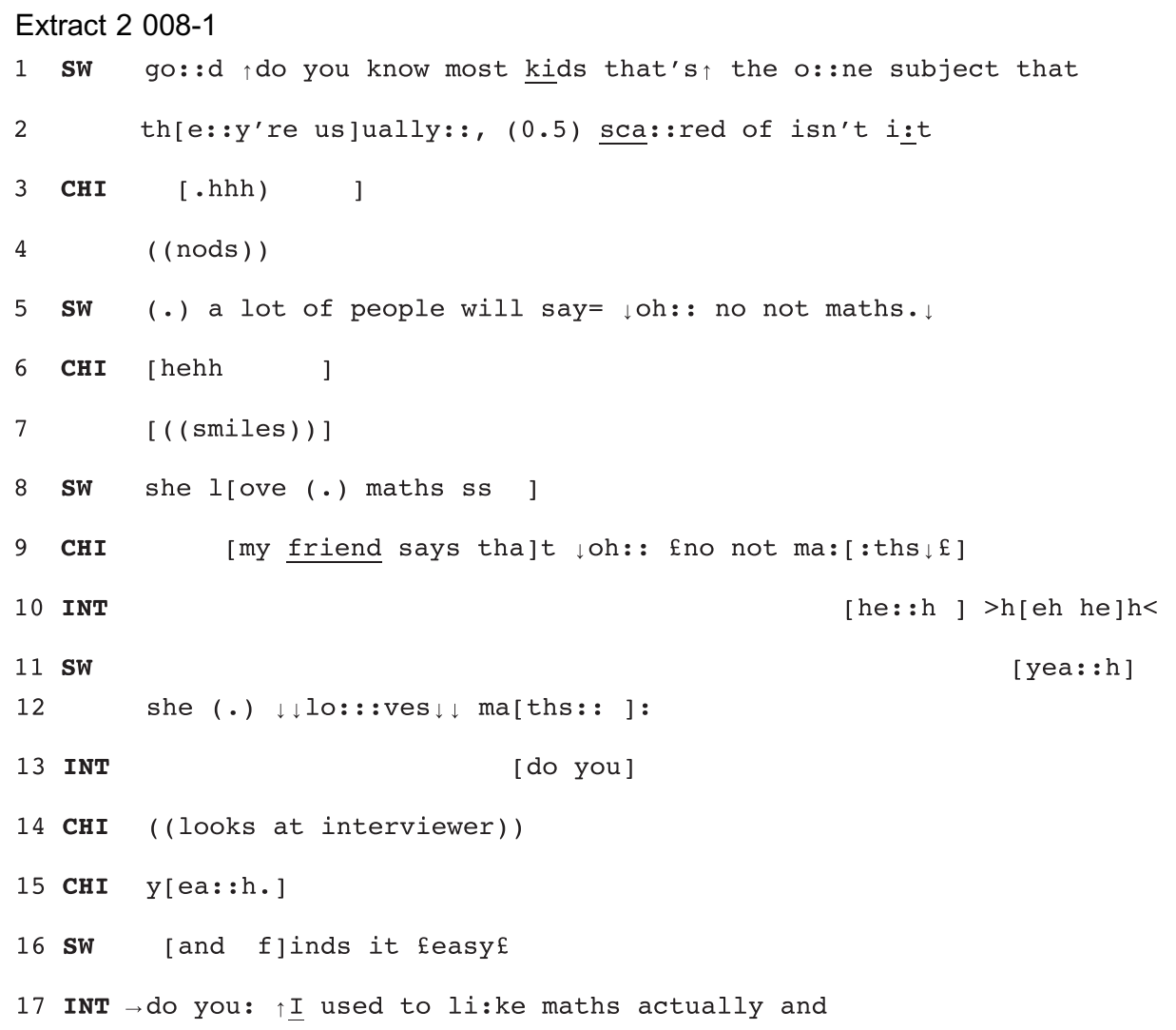




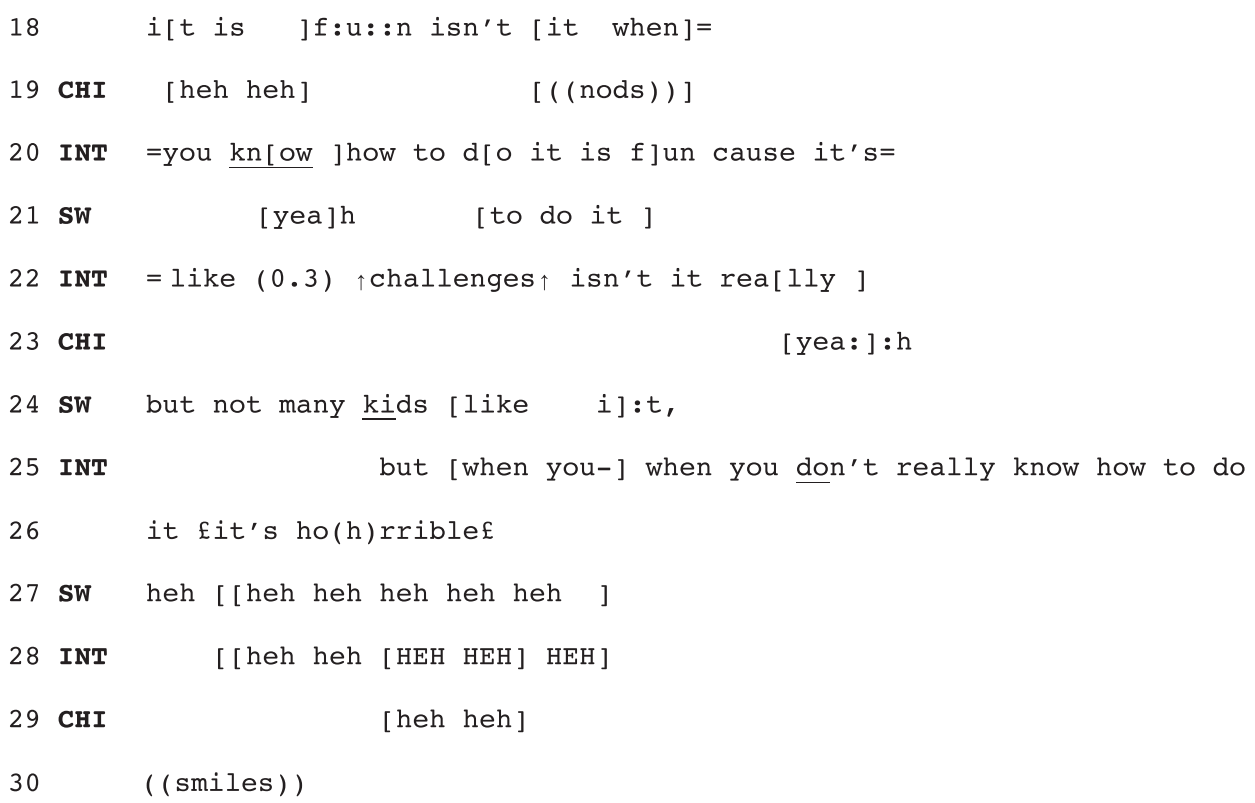

In this extract the interviewers' self-disclosure is occasioned by the social worker's other-disclosure as she informs the interviewer that the interviewee ' $\downarrow \downarrow$ lo::.:ves $\downarrow \downarrow$ maths::' 'and finds it £easy£'. The interviewer breaks into the social worker's turn at lines 11-12, inviting confirmation, before delivering the target expression ' $\uparrow$ I used to li:ke maths actually'. The turn final 'actually' marks the turn as informative (Clift, 2001) and displays the disclosure as volunteered and "over and above what is mandated by the interactional business at hand" (Antaki et al., 2005, p. 187). As such, it is brought off as a self-disclosure.

We can also note that by disclosing her own fondness of mathematics, describing this as ' $f: u:: n$ ' the interviewer delivers an assessment that builds on the interviewee's prior assessment and confirmation, at line 15, that she ' $\downarrow \downarrow$ lo::.:ves $\downarrow \downarrow$ maths::'. In contrast to extract 1, where the interviewee proffered assessments that upgrade the interviewer's assessment, the agreement tokens delivered by the interviewee throughout this sequence comprise basic agreement. As Shakespeare (1998) suggests, children are treated as less than full members, and their lack of competence may be oriented to by adults. By breaking into the interviewee's turn at line 15 the social worker orients to the interviewee's limited rights to engage in interaction. This overlap is resolved as the child drops out and the social worker produces an affiliative assessment on the child's behalf 'and finds it £easy£'. The interviewer subsequently invites the interviewee to confirm this before delivering the target TCU ' $\uparrow$ I used to li:ke maths actually'. The interviewee affiliates with this assessment, laughing and nodding in overlap with the interviewer's talk as she continues to build on the 'f:u::n' nature of mathematics. The interviewer describes mathematics as 'like (0.3) $\uparrow$ challenges $\uparrow$, ', inviting a response with the turn terminal 'isn't it really'. The interviewee enters the talk by acknowledging this with a basic agreement 'yeah'. In the turn at lines 25-26 the interviewer builds on the social worker's claim that 'not many kids like i:t,'. The laughter particle in the turn terminal item 'ho (h)rrible£' invites shared laughter, which is associated with consensus and rapport (Adelswärd and Öberg, 1998), demonstrating like-mindedness (Wilson et al., 2007).

It is easy to appreciate why such self-disclosures are typically confined to the opening phase of interviews, the aim of which is to build rapport with interviewees. In everyday talk, self-disclosures make relevant recipients' second disclosures (Sacks, 1992). Further, in both examples officer's self-disclosures take the form of assessments that trade on and build off interviewees' prior assessments and as such are mobilized to build extended sequences of rapport. These extended sequences shift the trajectory of the ongoing talk and would be disruptive in sequences where the aim is to encourage an uninterrupted free narrative account or to ask "appropriate questions that assist further recall" (ABE, p. 76). This would potentially hinder evidence gathering and preclude further information being provided. However there are strategies used by officers to 'personalize the interview' outside of the opening phase. The analysis now turns to these strategies.

\subsection{Self-deprecating self-reference}

This section examines instances of SDSR. The aim is to explicate the interactional work that is done by these instances of self-reference. Within the wider literature such instances of self-reference are conceptualized as examples of self-disclosure (e.g. Vallano and Schreiber Compo, 2011). We show how SDSRs are designed most immediately to manage the matters of responsibility implicated in environments in which some source of interactional trouble arises, typically problems in hearing, 
speaking or understanding that engender repair by the interviewee. By delivering these SDSRs police officers claim responsibility for the source of the trouble and work to avoid the implication that trouble arose due to a problem with the interviewees' speaking or that interviewers are failing to "listen to the witness" (ABE, p. 11). An example is given below;

\section{Extract 3 015-01}

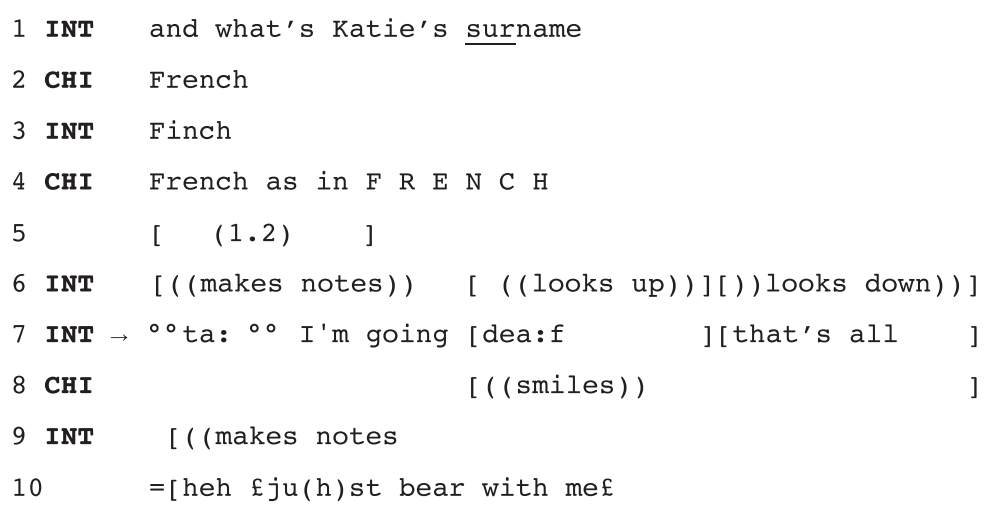

At line 7 the interviewer delivers an SDSR following other initiated self-repair. Following the erroneous verbatim repeat of the surname 'French' and its subsequent repair by the interviewee (line 4) the interviewer delivers an account for the mishearing with 'I'm going dea:f that's all heh £ju(h)st bear with me£='. We can note that the SDSR takes the form of an account that involves 'fault' on the part of the interviewer. As Robinson (2006, p. 139) notes, "other-initiated repair is vulnerable to communicating a stance that responsibility for the trouble belongs to the speaker of the talk that inspired repair initiation". The inference that responsibility lies with the interviewee is made available- specifically, that the trouble arose as a result of problems with the interviewee's speaking (such as mispronunciation or ambiguity). Managing relationships is an essential feature of other-initiation of repair and in this example the SDSR clarifies the interviewer's interactional stance regarding trouble responsibility- this lies with the interviewer and their faults (going deaf), not with the interviewee. There is a particular consideration that must be managed when initiating repair on interviewee's talk in the institutional environment of the police-witness interview. This is the demand for effective rapport building, which involves investigators being attentive to interviewees' talk and embodied interaction (St Yves, 2006). Note that the example above does not call into question the interviewer's attention toward the interviewee, such as the following example from an American pediatric visit.

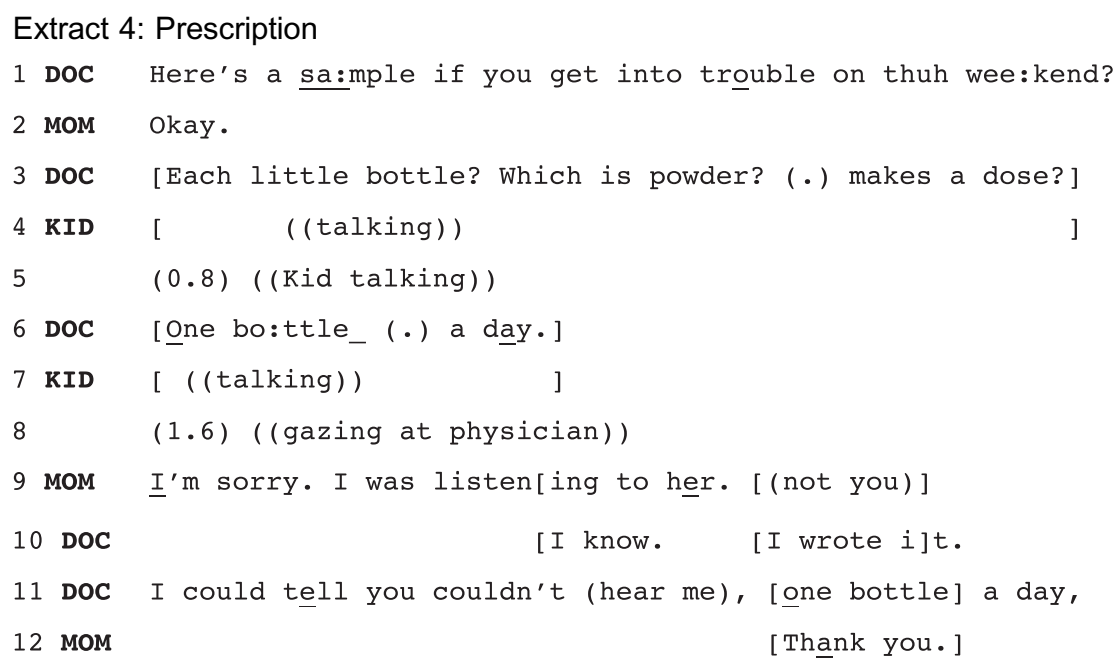

(from Robinson, 2006, p. 147)

Similarly to the examples from our data, the repair related offense account at line 9 involves 'fault' on behalf of the OIR producer. However the matter is formulated as a failure to listen to the physician. Such an account is at odds with institutional goals to listen to witnesses within the police interview and as such, examples that involve a failure to listen are absent from our materials. 
In extract 3, by claiming the fault to be a matter of auditory impairment the officer manages the demands of rapport building and the need to make the interviewee feel as if they are being listened to. These matters will be discussed further in the subsequent sections of the analysis as we examine the practice in further detail. A further point to note is that the example in extract 3 is delivered concurrently as the interviewer makes written notes. As Frohlich (1995) notes, because of the delay introduced when writing down what another person has said, note taking provides an additional space for one to elaborate their talk. It is during these lags associated with note taking that SDSRs are typically produced.

\subsection{Self-deprecating self-reference manage responsibility for other initiation of repair}

Accounts built with SDSR communicate the stance that responsibility for the trouble lies with the interviewer rather than the interviewee, whose talk engendered the repair initiation. This is important, as repeated questioning may cause witnesses to "lose self-confidence" (ABE, 2011, p. 79), which is detrimental as interviewers must make witnesses feel secure and confident with the interview situation. Let us consider the following example, where the interviewee describes how she met the alleged perpetrator.

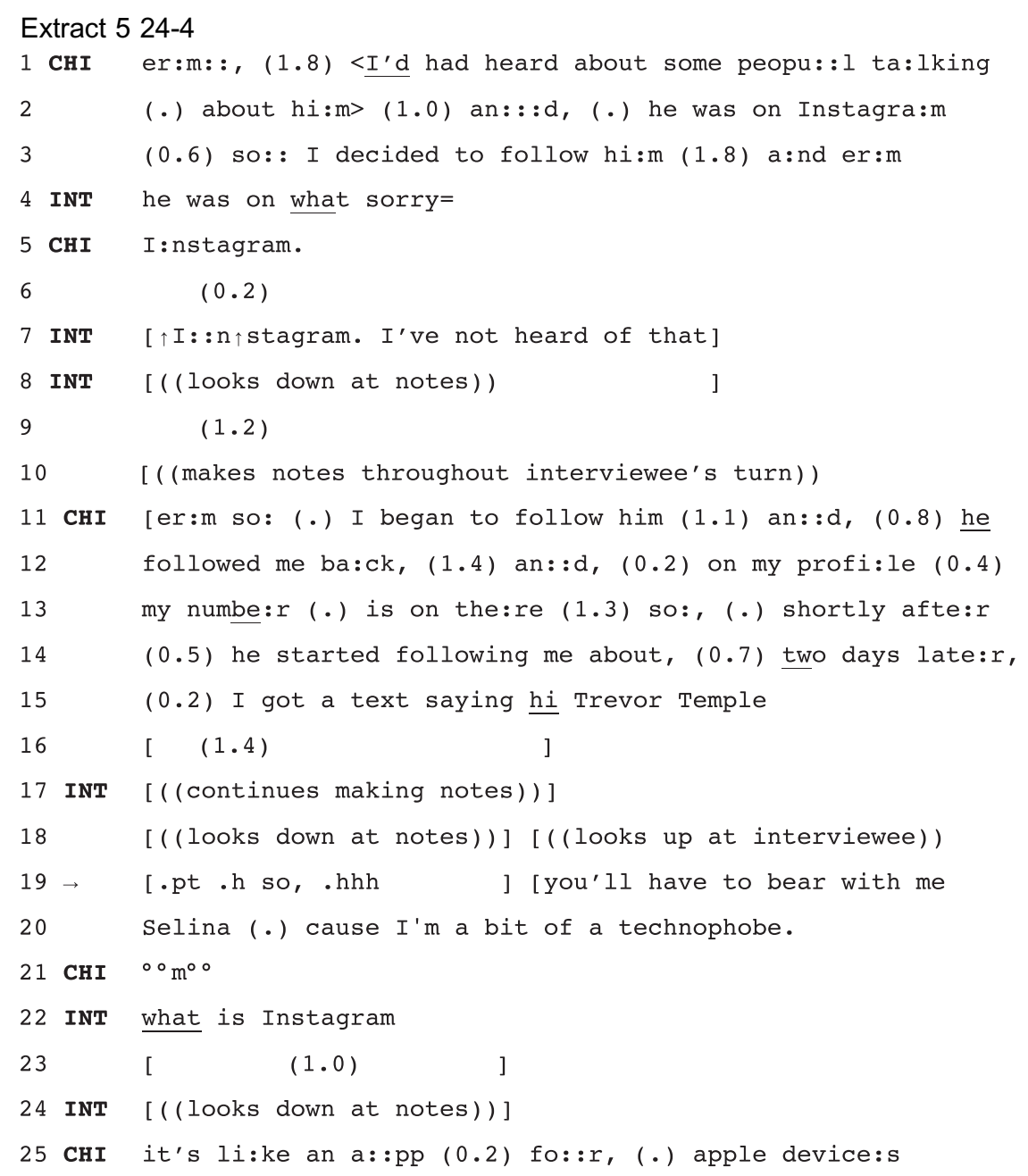

At the start of the extract the witness describes coming into contact with the alleged perpetrator over the internet (Instagram is a social media site for sharing photographs). The interviewer breaks into the interviewee's turn and initiates repair with 'he was on what sorry'. This initiation of repair followed by an apology orients to the commission of a possible offense and as such communicates the stance that responsibility for the trouble belongs to the interviewer, as the speaker (Robinson, 2006). The subsequent verbatim repeat treats the problem as one of hearing. The second possible repair initiator ' $\uparrow \mid:: n \uparrow$ stagram. I've not heard of that' treats the verbatim repeat as inadequate and casts the problem as one of understanding.

This second possible repair initiator (line 7) takes the form of a my-side telling whereby the speaker tells 'their own side' of a relevant matter and fishes for a response rather than directly asking for one (Pomerantz, 1980). Further, as an 'out-loud' 
(Schegloff, 1988), post-completion musing (Schegloff, 2007), this turn might only weakly make a response relevant next. We can also note that the interviewer does not direct her gaze at the interviewee to mobilize response, instead she looks down at her notes and continues to do so during the subsequent lag in the talk (line 9). Unsurprisingly, the interviewee does not orient to this possible repair initiator as she continues to describe meeting the alleged perpetrator (lines 11-15). At the next transition relevant place, following a gap during which the interviewer continues to make notes, the officer comes in with the target turn 'you'll have to bear with me Selina (.) cause I'm a bit of a technophobe.'. There are several design features that work together to assign responsibility for the trouble source to the interviewer. First, the turn initial 'you'll have to bear with me' is an idiomatic expression that implies that the recipient must be patient with the speaker- in this instance the interviewee must be patient with the interviewer's lack of understanding of technology. The repair-related offense account (Robinson, 2006) 'cause l'm a bit of a technophobe' involves 'fault' on behalf of the interviewer- she is ignorant of technological advances and as such is unfamiliar with Instagram. This is a dispositional account that suggests a general lack of understanding of technology. As such, in assigning fault we should look to the interviewer, rather than the particular circumstances of the current interaction and the interviewee's failure to adequately describe a piece of technology with which her recipient is unfamiliar, thereby exercising poor recipient design.

In sum, in this example we can see that, as Robinson (2006) notes, repair-related offense accounts manage trouble responsibility by invoking 'fault' on behalf of OIR producers. SDSRs produced in the environment of other initiation of repair are a way of managing the relational issue of responsibility for repair-related trouble. Given institutional goals to make witnesses feel secure and confident with the interview situation (ABE, 2011), including making children feel as if they are being listened to and understood, a crucial feature of these SDSRs is their proposal that trouble responsibility is a matter of the interviewer's impairment (rather than, for example, a lack of attention). It is this feature to which the analysis now turns.

\subsection{Self-deprecation as interviewer impairment}

So far the analysis has shown how SDSRs manage responsibility in environments of repair. A further live consideration in the institutional context of the police-witness interview is the need to establish 'mutual attention' in order to facilitate rapport. This involves "communicating the interviewer's focus on the source" (Abbe and Brandon, 2013, p. 210). As such, failure to adhere to the basic principle "listen to the witness" (ABE, p. 11) is an accountable matter. The SDSRs in our materials manage this by formulating the trouble as a matter of impairment rather than any other consideration, for example a lack of attention. Consider the following example (an extended version of extract 3 ), taken from near the beginning of the questioning phase.

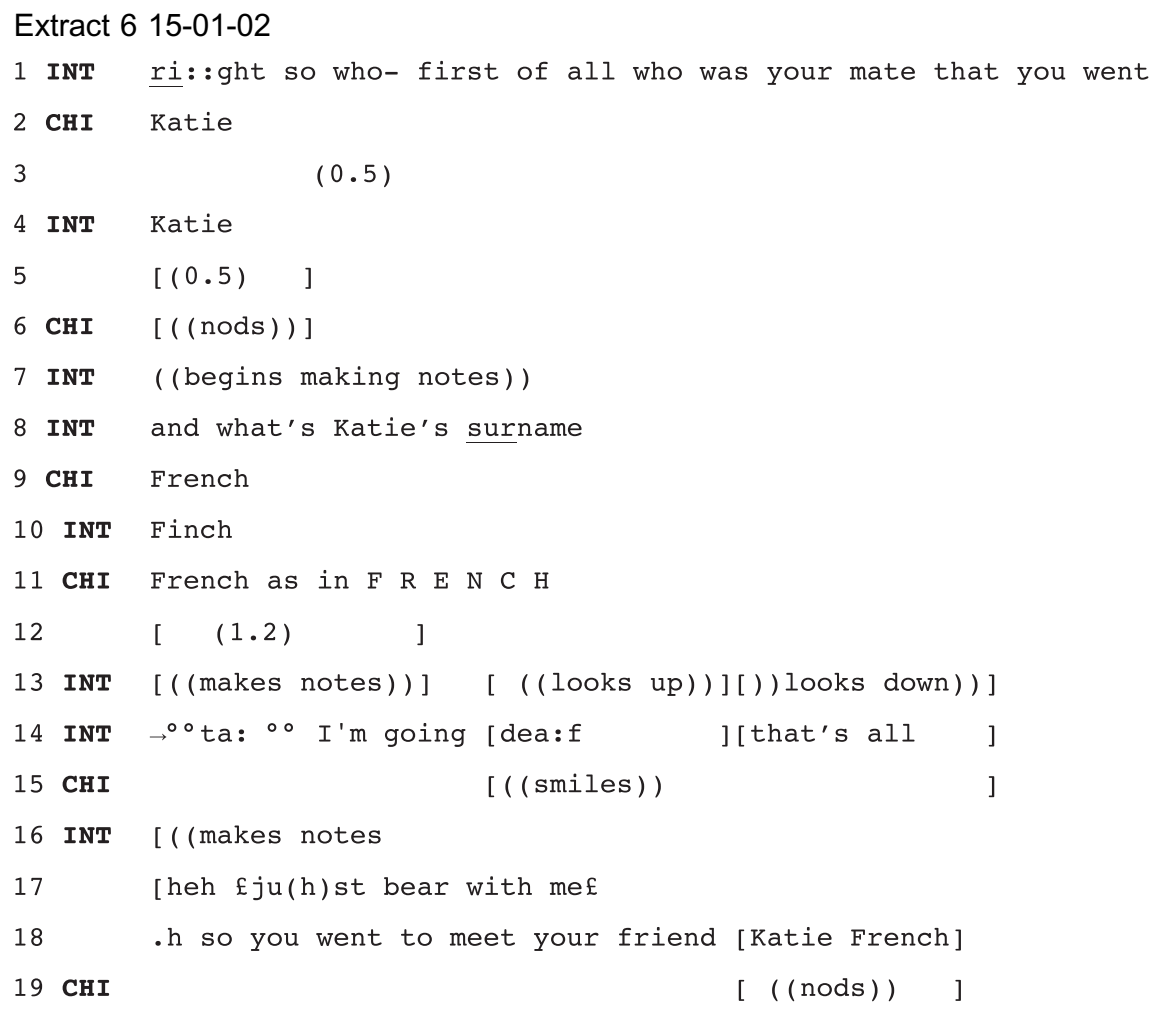


In this example the interviewer erroneously repeats the name 'French' as 'Finch'. Due to the necessity of anonymising all data before removal from police premises, involving the removal of all names and identifying information, it is not possible to state whether this is produced as a repair initiation (as would be indicated by a rising intonation) or whether this is a third position repeat delivered to explicitly register this new information. Nevertheless, the turn engenders a repair relevant response. The interviewee initiates repair with a verbatim repeat and an alphabetical spelling of the name. This leaves open the possibility that trouble responsibility lies with the interviewee- that a problem with their speaking necessitated the spelling out of the name. The interviewer subsequently begins to make notes, retrospectively identifying the repair as recordable (Komter, 2006), she receipts the repair 'ta' and provides an account; 'l'm going dea:f that's all heh $£ j u(h)$ st bear with me£='. Several features of this turn work together to formulate the trouble as a result of the interviewer's impairment rather than any other consideration. First, the problem is formulated as a matter of auditory impairment, refuting the notion that the problem lies with the interviewee's speaking. That the speaker is 'going' deaf implies that this matter is ongoing and enduring, rather than having been occasioned by the interaction that is taking place at that particular moment. 'That's all' minimizes the issue and refutes the notion that any other consideration (a lack of attention, problems with the interviewee's speaking) has caused the trouble. Finally, the turn terminal idiomatic ' $£ j u(h) s t$ bear with me£=' appeals to the interviewee to be patient with the interviewer and her auditory problems.

The appeal for the interviewee to ' $£ j u(h) s t$ bear with me£=' is also an orientation to the interviewer's note taking- she begins making notes at line 7 and continues to do so throughout the extract. Excessive note taking may distract witnesses (ABE, 2011), adversely impacting on rapport (Booth et al., 2004). As such it is advisable that practitioners develop strategies to minimize the impact of note taking tasks (Greatbatch et al., 1995). One such strategy identified by Booth, Robinson and Kohannejad, is to engage in 'chatter' and to offer verbal and nonverbal clues that one is listening. Here the interviewer achieves this by delivering the target expression during the lag introduced by notetaking and briefly directing her gaze at the interviewee (line 13) to signal attention.

A similar pattern is observable in the following fragment.

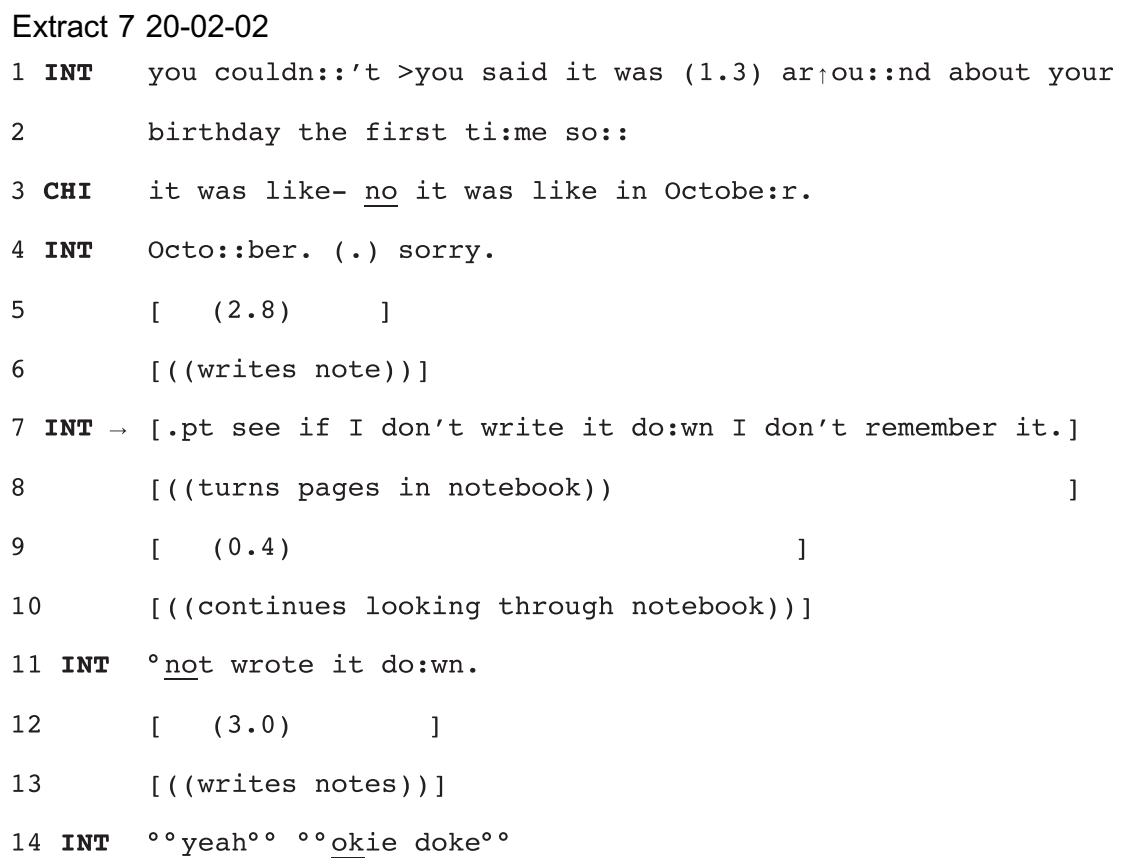

Earlier in the interview, the interviewee referred to the alleged incidents with the perpetrator having begun by the time of her birthday, in November, likely first taking place in October (data not shown). As the interviewer summarizes the key points from the interview, she states 'you said it was (1.3) ar $\uparrow$ ou::nd about your birthda:y the first ti:me so::'. The interviewee repairs this and re-iterates her earlier statement that 'no it was like in Octo:ber.'. The interviewer's subsequent apology based receipt orients to the commission of a possible offense. There is then a lag in the conversation as the interviewer makes notes (lines 5,6). She then flicks through her notebook and concurrently delivers the target turn 'see if I don't write it do:wn I don't remember it.'. This example appears to be a deviant case as it is the interviewee, rather than the interviewer, who initiates repair by correcting what the interviewer has said. This exposed correction (Jefferson, 1983) implicates fault on behalf of the interviewer and this fault is mitigated by the account at line 7 . However the interviewer's 
failure in recollection makes available the inference that this was caused because of considerations such as a lack of attention or faults with the interviewee's speaking. That the account is formulated as a matter of the interviewer's impairment refutes this. Note the turn initial 'see', which presents this as something that is expectable and recognizable, that the interviewer is prone to forgetting details if she does not write these down.

The second thing to note is the timing of the delivery of the SDSR during the lag in the conversation while the interviewer looks back through her notes, which provides the opportunity to elaborate her talk and deliver the SDSR (c.f. Frohlich, 1995). The SDSR also constitutes 'chatter' (Booth et al., 2004) that allows the interviewer to maintain mutual attention and involvement while she is engaged in the activity of looking back through her notes.

In sum, the SDSRs in our materials manage to demands of rapport building by claiming responsibility for repair related trouble. A crucial feature is that such trouble is proposed to be a result of interviewers' impairment - they are prone to such errors. Consequently, when assigning responsibility for repair related trouble, we should look to the interviewer and their faults, rather than anything within the interaction at that particular moment, such as a failure to listen. A further crucial feature of these turns is the typical timing of their delivery while interviewers are engaged in note-taking activities. These SDSRs constitute relevant, off topic 'chatter' and allow interviewers to maintain involvement during the lag introduced by note taking. These SDSRs are delivered at various positions within TCUs. Although there is diversity in the sequential positioning of these turns, each takes the form of a repair related offense account cast in terms of the interviewer's failure in hearing or remembering.

\section{Discussion}

This paper's specific purpose was to examine how police officers personalize the investigative interview and 'talk about themselves' (ABE, 2011, p. 118) in interviews with children reporting their being victim of alleged sexual offenses. Although best practice guidelines stress the importance of personalizing the interview, particularly during the opening phase in order to enhance the quantity and quality of information obtained, clear unambiguous self-disclosures were rare. These self-disclosures are designed to affiliate with witnesses, taking the form of assessments that build on and trade off the interviewee's prior assessment and are mobilized to build extended sequences of rapport. The analysis also revealed how instances of self-deprecating self-reference may be used by the interviewer to claim responsibility for a trouble source turn (typically, although not exclusively, in environments of OIR). Other initiations of repair are susceptible to communicating the stance that the source of the trouble is the responsibility of the speaker of the talk that engendered the repair initiation (Robinson, 2006). That is, that responsibility lies with the interviewee. In our materials these instances of self-deprecation function as accounts, but speakers claim disproportionate responsibility rather than disclaiming liability $(Y u, 2013)$. A key feature of the offense related accounts in the police interviews is that the trouble is formulated as a matter of the interviewer's impairment (such as having a bad memory or auditory impairment). These dispositional accounts propose that the trouble has occurred due to the interviewer and their own faults, rather than any particular circumstances of the current interaction, such as a failure to listen. As such, these accounts manage the conflicting demands of rapport building and the requirement to make children feel as if they are being listened to and understood, on the one hand, and the need for effective evidence gathering, which often requires intensive and repeated questioning, on the other. Our analysis then, has shown skillful ways in which interviewers may engage in repeated questioning such as not to cause witnesses to "lose self-confidence" (ABE, 2011, p. 79). Engaging in such practices may have implications for both the quantity and quality of information obtained. However arguably SDSR should be used sparingly as excessive self-deprecation may result in a lack of confidence in the interviewer.

This article extends our understanding of how interviewing officers 'talk about themselves' and personalize the interview, as recommended by best practice guidelines. In spite of the importance that interviewers get this 'right' with inappropriate self-disclosures potentially undermining respect for the interviewer (Abbe and Brandon, 2013; Vallano and Schreiber Compo, 2011) hence damaging the interview, there is scant information about how interviewers actually engage in 'self-disclosure' during the course of interviews, and little guidance regarding how they should do so. This paper has identified "approaches to interviewer self-disclosure that have the potential to facilitate witness recall without running the risk of being perceived as unprofessional or context-inappropriate" (Vallano and Schreiber Compo, 2011, p. 266). The 'opening phase' of interviews provides the space for officers to deliver clear, unambiguous self-disclosures with the aim of eliciting a similar self-disclosure from the interviewee. The aim of the subsequent free-narrative phase of the interview is for officers to 'initiate an uninterrupted free narrative account of the incident' (ABE, 2011, p. 74). Such self-disclosures would be inappropriate at this stage of the interview as these may impede the account being given by the interviewee. Similarly, the aim of the questioning phase is to elicit further detail with the interviewer "asking appropriate questions that assist further recall" (ABE, 2011, p. 76). Here self-disclosures, which provide for the relevance of the recipient's second self-disclosures, would interrupt the trajectory of the ongoing talk and preclude further information being provided. It is also likely that these may be considered, by interviewers and by complainants, as inappropriate to the context outside of interviews' opening phase. However, rapport should not be envisaged as a stock that is built at the start of the interview 
and then lasts for the interview's duration (Walsh and Bull, 2012). Rather, "it begins when the interviewer first meets the witness and continues throughout the interview" (ABE, p. 71). Indeed, Walsh and Bull found that in interviews where interviewers failed to maintain rapport, incomplete accounts were gathered. On the other hand, these authors found that when rapport as not only skillfully built but maintained throughout the interviews, the likelihood of gathering comprehensive accounts significantly increased. In the present study our analysis has elucidated how officers may continue to personalize the interview (and thus, maintain rapport) beyond the opening phase. A clear implication of our analysis is that, in line with Vallano and Shreiber Compo's arguments, and in contrast with St-Yves' (2006) recommendations of interviewer professionalism, precluding self-disclosure, self-disclosure should not be disqualified as an effective rapport building technique.

Although the instances of self-deprecating self-reference outlined in the second part of the analysis are a strategy used by officers to ostensibly 'talk about themselves' they in fact do not function to reveal personal information. Rather they are designed to manage the conflicting demands of rapport building and making interviewees feel that they are being listened to and understood on the one hand, and effective evidence gathering, on the other. The sequential design and interactional function of instances of self-reference is something that is unappreciated in previous research that measures the proportion of supportive statements (e.g. Teoh and Lamb, 2013) or self-disclosures (e.g. Vallano and Schreiber Compo, 2011) and their effects on the quality and quantity of information obtained. Interactional processes are at work here and an understanding of these are needed so that researchers can most effectively recommend strategies through which interviewers may improve the quality of interactions in the interview setting. This paper also contributes to work on practices of offense related accounts in environments of repair (Robinson, 2006). Our work has shown how the nature of such accounts may be constrained by institutional obligations - in our materials, the requirement to make complainants feel as if they are being listened to. Accounts that involve interviewers' impairment are a strategy for managing these demands.

\section{Appendix A. Transcription conventions}

[]

$\downarrow \uparrow$ Underlining

CAPITALS

i know ${ }^{\circ}$

I do::nt know

hhhh

.hhhh

Pauses in tenths of a second

A micropause, less than $0.1 \mathrm{~s}$

Beginning and end of overlapping talk

Notable pitch changes

Emphasis

Louder than the surrounding talk

Quieter than the surrounding talk

really?

Elongated sound

Outbreath

reallyi

Inbreath

no.

'Questioning' intonation

Weak 'questioning' intonation

no,

Falling intonation

$>$ really<

Weak rising intonation

heh heh

Increased speed

Laughter

st(h)o(h)p i(h) Laughter within speech

$£ \quad$ 'Smiley voice'

bu-u- 'Cut off' of the preceding sound

\section{References}

Abbe, A., Brandon, S., 2013. The role of rapport in investigative interviewing: a review. J. Investig. Psychol. Offender Profil. 10, $237-249$.

Adelswärd, V., Öberg, B., 1998. The function of laughter and joking in negotiation activities. Humor 11, 411-430.

Antaki, C., Barnes, R., Leudar, I., 2005. Self-disclosure as a situated interactional practice. Br. J. Soc. Psychol. 44, 181-199.

Antaki, C., Richardson, E., Stokoe, E., Willot, S., 2015. Dealing with the distress of people with intellectual disabilities reporting sexual assault and rape. Discourse Stud. 17, 415-432.

Back, C., Gustafsson, P.A., Larsson, I., Berterö, C., 2011. Managing the legal proceedings: An interpretative phenomenological analysis of sexually abused children's experience with the legal process. Child Abuse Negl. 35 (1), 50-57.

Booth, N., Robinson, P., Kohannejad, J., 2004. Identification of high-quality consultation practice in primary care: the effects of computer use on doctor-patient rapport. Inform. Primary Care 12, 75-83.

Clark, C., Drew, P., Pinch, T., 2003. Managing prospect affiliation and rapport in real-life sales encounters. Discourse Stud. 5, 5-31.

Clift, R., 2001. Meaning in interaction: the case of actually. Language 77, 245-291. 
Collins, N.L., Miller, L.C., 1994. Self-disclosure and liking: a meta-analytic review. Psychol. Bull. 116, 457-475.

Collins, R., Lincoln, R., Frank, M.G., 2002. The effect of rapport in forensic interviewing. Psychiatry Psychol. Law 9, 69-78.

Collins, R., Lincoln, R., Frank, M.G., 2005. The Need for Rapport in Police Interviews. Bond University Available from: http://epublications.bond. edu.au/hss_pubs/38

Edwards, D., 2000. Extreme case formulations: softeners, investment, and doing nonliteral. Res. Lang. Soc. Interact. 33, $347-373$.

Fisher, R.P., Geiselman, R.E., 1992. Memory-Enhancing Techniques for Investigative Interviewing: The Cognitive Interview. Springfield, IL, Charles C. Thomas.

Frohlich, D., 1995. Requirements for interpersonal information management. In: Thomas, P.J. (Ed.), Personal Information Systems: Business Applications. Nelson Thornes Ltd., Cheltenham, England, pp. 133-153.

Greatbatch, D., Heath, C., Campoin, P., Luff, P., 1995. How do desk-top computers affect the doctor-patient interaction. Fam. Pract. 12, 32-36.

Greeson, M.R., Campbell, R., Fehler-Cabral, G., 2014. Cold or caring? Adolescent sexual assault victims' perceptions of their interactions with the police. Violence Vict. 29, 636-651.

Hepburn, A., Bolden, G.B., 2017. Transcribing for Social Research. Sage, London.

Heritage, J., Lindström, A., 1998. Motherhood, medicine and morality: scenes from a medical encounter. Res. Lang. Soc. Interact. 31, $397-438$.

Hershkowitz, I., 2011. Rapport building in investigative interviews with children. In: Lamb, M.E., La Rooy, D.J., Malloy, L.C., Katz, C. (Eds.), Children's Testimony. 2nd ed. Wiley-Blackwell, Chichester, England, pp. 109-128.

Holmberg, U., 2004. Police Interviews with Victims and Suspects of Violent and Sexual Crimes: Interviewee's Experiences and Interview Outcomes (Doctoral dissertation). Psykologiska institutionen.

Jefferson, G., 1983. On embedded and exposed correction in conversation. Stud. Linguist. 14, 58-68.

Komter, M.L., 2006. From talk to text: the interactional construction of a police record. Res. Lang. Soc. Interact. 39, $201-228$.

Leudar, I., Antaki, C., Barnes, R., 2006. When psychotherapists disclose personal information about themselves to clients. Commun. Med. 3, $27-41$.

Newberry, J.J., Stubbs, C.A., 1997. Advanced Interviewing Techniques. Bureau of Alcohol Tobacco and Firearms National Academy, Glynco, Georgia.

Pomerantz, A., 1980. Telling my side: 'Limited access' as a 'fishing' device. Sociol. Inq. 50, 186-198.

Pomerantz, A., 1986. Extreme case formulations: a way of legitimizing claims. Hum. Stud. 9, 219-229.

Quas, J.A., Lench, H.C., 2007. Arousal at encoding, arousal at retrieval, interviewer support, and children's memory for a mild stressor. Appl. Cogn. Psychol. 21 (3), 289-305.

Roberts, K., Lamb, M.E., Sternberg, K.J., 2004. The effects of rapport building on children's reports of a staged event. Appl. Cogn. Psychol. 18, 189-2002.

Robinson, J.D., 2006. Managing trouble responsibility and relationships during conversational repair. Commun. Monogr. 73, $137-161$.

Sacks, H., 1992. Lectures on Conversation. Blackwell Publishing, Oxford, England.

Schegloff, E.A., 1988. On an actual virtual servo-mechanism for guessing bad news: a single case conjecture. Soc. Probl. 35, 442-457.

Schegloff, E.A., 2007. Sequence Organization in Interaction: Volume 1: A Primer in Conversation Analysis. Cambridge University Press, Cambridge, England.

Shakespeare, P., 1998. Aspects of Confused Speech: A Study of Verbal Interaction Between Confused and Normal Speakers. Lawrence Erlbaum Associates, New Jersey.

Soukara, S., Bull, R., Vrij, A., 2002. Police detectives' aims regarding their interviews with suspects: any changes at the turn of the millennium? Int. J. Police Sci. Manag. 4, 110-114.

Spencer-Oatey, H., 2000. Rapport management: a framework for analysis. In: Spencer-Oatey, H. (Ed.), Culturally Speaking: Managing Rapport Through Talk Across Cultures. Continuum, London, England, pp. 11-46.

Sprecher, S., Treger, S., Wondra, J.D., Hilaire, N., 2013. Taking turns: reciprocal self-disclosure promotes liking in initial interactions. J. Exp. Soc. Psychol. 49, 860-866.

St Yves, M., 2006. The psychology of rapport: five basic rules. In: Williamson, T. (Ed.), Investigative Interviewing: Rights, Research and Regulation. Willan Publishing, Devon, England, pp. 97-135.

Stokoe, E., 2009. I've got a girlfriend": police officers doing 'self-disclosure' in their interrogations of suspects. Narrat. Inq. 19, 154-182.

Teoh, Y.S., Lamb, M., 2013. Interviewer demeanor in forensic interviews of children. Psychol. Crime Law 19, 145-159.

UK Ministry of Justice, 2011. Achieving Best Evidence in Criminal Proceedings. Retrieved from: http://www.justice.gov.uk/downloads/ victims-and-witnesses/vulnerable-witnesses/achieving-best-evidence-criminal-proceedings.pdf

Vallano, J.P., Schreiber Compo, N., 2011. A comfortable witness is a good witness: rapport-building and susceptibility to misinformation in a simulated mock-crime interview. Appl. Cogn. Psychol. 25, 960-970.

Westcott, H., Kynan, S., 2006. Interviewer practice in investigative interviews for suspected child sexual abuse. Psychol. Crime Law 12, $367-382$. Wilson, B.T., Müller, N., Damico, J., 2007. The use of conversational laughter by an individual with dementia. Clin. Linguist. Phon. 21, $1001-1006$. Wood, J.M., McClure, K.A., Birch, R.A., 1996. Suggestions for improving interviews in child protection agencies. Child Maltreat. 1, $223-230$. Walsh, D., Bull, R., 2012. Examining rapport in investigative interviews with suspects: Does its building and maintenance work?

Yu, C., 2013. Two interactional functions of self-mockery in everyday English conversations: A multimodal analysis. J. Pragmat. 50, 1-22.

Carrie Childs is a Lecturer in Psychology at the University of Derby. Her research interests are language and social interaction in a range of settings using discursive and conversation analytic techniques. She has particular expertise in family interaction and investigative interviewing.

Dave Walsh is a Reader in Criminal Investigation in the International Policing and Justice Institute, at the University of Derby. A former investigator with over twenty years' professional experience, Dave completed his PhD in 2011, which examined the interviewing of suspects in England and Wales. Dave has written many publications, book chapters as well as co-authoring a book, as well as presenting his research at several international conferences. He also advises both serving practitioners and governments across the world as to best practices involving the interviewing of both children and adults. 